
\title{
25 Research Soure \\ Emission Inventory and Spatial Distribution of Particulate Matter from Dust Sources in Zhengzhou City, China
}

Huan Yang

Zhengzhou University

Xuan Song ( $\nabla$ songxuan@zzu.edu.cn )

Zhengzhou University https://orcid.org/0000-0001-9455-3850

Jiarui Song

No.1 Middle School of Zhengzhou

Qi Zhang

Zhengzhou University

Jian Cui

Henan Institute of Geological Survey

Shasha Yin

Zhengzhou University

\section{Research}

Keywords: PM emission, GIS and RS, Dust source, Emission inventory, Spatial distribution

Posted Date: January 7th, 2020

DOI: https://doi.org/10.21203/rs.2.20196/v1

License: (c) (1) This work is licensed under a Creative Commons Attribution 4.0 International License.

Read Full License 


\section{Abstract}

Background: With the rapid development of society and economy, Zhengzhou city, a new first-tier city in central China, is facing high levels of particulate matter (PM) pollution. Dust source has been generally recognized as one of the major source of PM emission that cannot be ignored. In this study, we aimed to establish an emission inventory of PM from dust source and characterize its spatial pattern in Zhengzhou, China.

Methods: A GIS $₫$ RS based approach was proposed to establish the emission inventory of total suspended particles (TSP), particulate matter 10 (PM 10 ) and particulate matter 2.5 (PM 2.5 ) from dust source. Bare ground, construction sites and paved roads in 2016 was recognized with high resolution remote sensing data.Technical Guidelines for Emissions Inventory of Particulate Matter Emitted from Dust Source recommended by the Ministry of Ecological Environment (MEP) was used to estimate PM emission, and a spatial grid of $3 \mathrm{~km} \times 3 \mathrm{~km}$ resolution was established to display the distribution of PM emission from different dust sources.

Results: The total emission of TSP, PM 10 and PM 2.5 in Zhengzhou was $237.5 \mathrm{kt} \cdot \mathrm{a}-1,103.7 \mathrm{kt} \cdot \mathrm{a}-1$ and $22.4 \mathrm{kt} \cdot \mathrm{a}-1$, respectively in 2016. Compared to other cities in China, the PM emission in Zhengzhou was at a relatively high level. Construction dust source was the main emission source in Zhengzhou, the TSP, PM 10 and PM 2.5 emission of which account for $76.42 \%, 89.68 \%$ and $88.39 \%$, respectively of the total emissions, followed by road dust source and soil dust source. Spatially, total TSP, PM 10 , PM 2.5 emission were larger in main urban areas including Jinshui, Zhongyuan, Erqi, Jingkai and other urban districts. Zhongmou, Xingyang and Xinzheng, which bordering with the main urban area, were also the area with high PM emission, while Dengfeng, Gongyi and other remote areas had relatively small emission of PM.

Conclusions: The GIS $₫$ RS based approach has good applicability for identifying the emission characteristics in urban area, and it is urgent for Zhengzhou city to take specific measures for the prevention and control of atmospheric pollution under the severe situation of high- level PM emission.

\section{Background}

With the rapid industrialization and urbanization of Chinese cities, air pollution has become one of the most serious environmental problem. Haze weather frequently occurs in autumn and winter, and the air quality becomes even worse in many developed cities[1-3]. Serious air pollution issue not only restricts the sustainable development of regional economy, but also brings great negative influence on human health[4]. As the major components of atmospheric pollutants, particulate matter (PM) has received much attention in the field of atmospheric environment research[5-7]. There are various sources of PM emission, of which dust source is the most common source in urban areas. Dust source refers to a certain range of atmospheric particulates that generated from loose surface and entered to the ambient air by natural and human factors, which can be divided into soil dust, construction dust, road dust and the field 
dust [8]. Studies have shown that the contribution rate of $\mathrm{PM}_{2.5}$ and $\mathrm{PM}_{10}$ emission from dust source account for $41.8 \%$ and $60.0 \%$, respectively in Nanchong [9], $16.7 \%$ and $23.6 \%$ in Haikou, respectively [10], $22.1 \%$ and $28.7 \%$ in Qingdao [11], and $30 \%$ and $42 \%$ in Tianjin[12], dust source has been generally recognized as one of the major source of PM emission that cannot be ignored.

Previous studies have made great efforts on the estimation of PM emission, nevertheless, most of these studies were carried out in big cities in developing countries such as Beijing, Shanghai in China[13-14], New Delhi in India[15], and focus more on the industrial and vehicle source of PM emissions[16-19], while few studies have been conducted to investigate the PM emission from dust source in medium-sized cities with rapid growth and severe air pollution problems. Zhengzhou, a fast-growing megacity city in the central area of China, is facing serious air pollution issue along with the rapid economic development and expansion of urban area. According to the investigation conducted by MEP in 2016, the air quality of Zhengzhou city was the seventh from the bottom among 74 major cities of China, and the number of days exceeding the national air quality standard of $\mathrm{PM}_{10}$ and $\mathrm{PM}_{2.5}$ accounted for about $70 \%[20]$. For better implementation of the action plan for the prevention and control of atmospheric pollution that issued by the State Council of China, it is urgent for Zhengzhou city to get more information about PM emission characteristics to enhance the pertinence and effectiveness of the prevention and control of atmospheric pollution.

Based on the high resolution image of ZY-3 satellite, the distribution of dust sources (bare ground, construction sites and paved roads) of Zhengzhou in 2016 was identified. The emission of TSP, $\mathrm{PM}_{10}$ and $\mathrm{PM}_{2.5}$ from different types of dust sources were estimated according to the Technical Guidelines for Emissions Inventory of Particulate Matter Emitted from Dust Source[21], and a grid model of $3 \mathrm{~km} \times 3 \mathrm{~km}$ resolution was established to demonstrate the spatial distribution of PM emission under the support of ArcGIS 10.2. It is expected that the results of this study could provide scientific reference for atmospheric pollution prevention and control.

\section{Materials And Methods \\ 2.1 Study area}

Zhengzhou City, the capital of Henan Province, is a new first-tier city with an area of $7446 \mathrm{~km}^{2}$. The geographic location is between $112^{\circ} 42^{\prime} \sim 114^{\circ} 14^{\prime} \mathrm{E}$ and $34^{\circ} 16^{\prime} \sim 34^{\circ} 58^{\prime} \mathrm{N}$ (Fig. 1). There are 10 municipal districts (Jinshui District, Zhongyuan District, Erqi District, Guancheng District, Huiji District, New hightech Zone, Economic Development Zone, Airport Economy Zone, Shangjie District, Zhengdong New District), 5 county-level cities (Gongyi City, Dengfeng City, Xinzheng City, Xinmi City, Xingyang City), and one county (Zhongmou County) in Zhengzhou. Zhengzhou City is characterized by the north temperate continental monsoon climate with an annual mean temperature of $13.9^{\circ} \mathrm{C}$, the annual average precipitation is $640 \mathrm{~mm}$, which concentrated in June, July and August. The average wind speed is $2.8 \sim$ $3.2 \mathrm{~m} / \mathrm{s}$, the maximum wind speed is $18 \sim 22 \mathrm{~m} / \mathrm{s}$, which mostly occurs in April or September. The soil 
types mainly include Cinnamon soil (62.5\% of the total area), fluvo-aquic soil (26.9\%), sandy soil (5.1\%), stony soil( $2.6 \%)$, coarse soil $(1.9 \%)$ and a small amount of red clay $(0.8 \%)$ and purple soil $(0.2 \%)$.

\subsection{Data processing and spatial mapping}

Remote sensing data used in this study was acquired from the Chinese Resource Satellite ZY-3. ZY-3 is China's first three linear array stereo mapping satellite, the maximum spatial resolution of which is $2.1 \mathrm{~m}$. Since the launch of the satellite in January of 2012, images from ZY-3 have been widely used in land surveying, territorial mapping, and ground information extraction[22-24]. Before identifying the distribution of emission source, ENVI 5.3 was used for the preprocessing of images, including radiometric calibration, geometric correction, image enhancement and splicing and clipping, the 1:50,000-scale topographic map was used for geometric correction, and the error was less than 0.5 pixels after correction.

The spatial distribution of bare ground, construction sites and different types of roads (national road, provincial road, county road and township road) were identified by visual interpretation in ArcGIS 10.2. Every piece of emission source was extracted as a shapefile, the attribute data of each shapefile included name, location, length, area and other association attributes. After the manual extraction, all the shapefiles were overlaid together and a new thematic layer was formed to calculate the emission of TSP, $\mathrm{PM}_{10}$ and $\mathrm{PM}_{2.5}$ with method recommended by the MEP, then a grid of $3 \mathrm{~km} \times 3 \mathrm{~km}$ resolution was established to display the spatial distribution of TSP, $\mathrm{PM}_{10}$ and $\mathrm{PM}_{2.5}$ emission from different dust sources.

\subsection{Methodology}

\subsubsection{Soil Dust}

Soil dust is generated from bare ground such as bare farmland, exposed mountains, tidal flats, dry river valleys, unhardened spaces. The influence factor of emission from soil dust include particle size distribution of surface soil, surface roughness, vegetation coverage, surrounding shielding conditions and meteorological conditions. Bare ground in this study mainly focuses on the farmland in the surrounding urban areas and the open land without hardening or greening.

The formulas for calculating emission of PM from soil dust sources are as follows:

$W_{S i}=E_{S i} \times A_{S}(1)$

$E_{S i}=D_{i} \times C \times(1-\eta) \times 10^{-4}(2)$

Where $W_{S i}$ is the total $P M_{i}$ emission, $t / a ; E_{S i}$ is the $P M_{i}$ emission coefficient, $t /\left(m^{2} \cdot a\right) ; A_{s}$ is the area of soil dust source, $\mathrm{m}^{2} ; D_{i}$ is the dust emission factor of $\mathrm{PM}_{\mathrm{i}}, \mathrm{t} /\left(10^{4} \mathrm{~m}^{2} \cdot \mathrm{a}\right) ; \eta$ is the dust removal efficiency by 
pollution control technology, \%. Since only the dust emission of the exposed ground was considered in this study, the removal efficiency of the exposed ground control efficiency was set to zero.

$D_{i}=k_{i} \times I_{w e} \times f \times L \times V(3)$

$C=0.504 \times u^{3} / P^{2}(4)$

Where $k_{i}$ is the percentage of $\mathrm{PM}_{\mathrm{i}}$ in soil dust. The recommended values of TSP, $\mathrm{PM}_{10}$ and $\mathrm{PM}_{2.5}$ are 1 , 0.30 and 0.05 , respectively; $I_{\text {we }}$ is the soil wind erosion index, which is 331 for TSP, 99 for $P_{10}$ and 17 for $\mathrm{PM}_{2.5}$ according to the soil texture of Zhengzhou. $\mathrm{f}$ is the ground roughness factor, the value of which is $0.5 ; \mathrm{L}$ is the unshielded width factor, and the value is $1.0 ; \mathrm{V}$ is the vegetation coverage factor, and the value is 0.9 . $\mathrm{C}$ is the climatic factor, $\mathrm{u}$ is the annual average wind speed, $\mathrm{m} / \mathrm{s}$; PE is the Thomthwaite Precipitation Index (evaporation index), and the PE formula is as follows:

$\mathrm{PE}=1.099 \times \mathrm{p} /\left[0.5949+\left(0.1189 \times \mathrm{T}_{\mathrm{a}}\right] \otimes 5\right)$

Where $\mathrm{p}$ is the annual precipitation, $\mathrm{mm} ; \mathrm{T}_{\mathrm{a}}$ is the annual average temperature, ${ }^{\circ} \mathrm{C}$.

The average wind speed of Zhengzhou is $1.984 \mathrm{~m} / \mathrm{s}$, the annual precipitation value is $833.1 \mathrm{~mm}$ and the annual average temperature is $16.5^{\circ} \mathrm{C}$ in 2016 .

\subsubsection{Construction dust}

Construction dust is the dust generated during the construction process, such as urban municipal infrastructure, the construction and demolition of building, the engineering of the equipment installation and building decoration. The influence factors of emission from construction dust source including construction area, construction time and PM emission coefficient. In this study, area of main building construction and decoration construction was considered as the construction area for the calculation of construction dust emission.

The calculation formulas for the emission from construction dust are as follows:

$W_{C i}=E_{C i} \times A_{C} \times T(6)$

$E_{C i}=2.69 \times 10^{-4} \times(1-\eta) \nabla 7 \nabla$

Where $W_{C i}$ is the total $\mathrm{PM}_{i}$ emission of the construction dust, $t / a$; $E_{C i}$ is the average $\mathrm{PM}_{i}$ emission coefficient of the entire construction zone, $t /\left(\mathrm{m}^{2}\right.$.month); $A_{C}$ is the area of construction zone, $\mathrm{m}^{2} ; \mathrm{T}$ is the period of construction activities, which is generally calculated by the number of construction days/30 (according to the survey, the average construction days in Zhengzhou was $179 \mathrm{~d}$ in 2016); $\eta$ is the removal efficiency by pollution control technology, \%.

\subsubsection{Paved road dust}


Road dust refers to the dust that generated from paved roads and entering the ambient air under dynamic conditions (wind power, motor vehicle rolling, crowd activities, etc.). The paved roads of Zhengzhou can be divided into four categories including national roads, provincial roads, township roads and county roads.

The calculation formulas of PM emission from each category of paved roads are as follows:

[Due to technical limitations, these formulas could not be displayed here. Please see the supplementary files section to access these formulas.]

8

9

Where $W_{R i}$ is the total emission of $P M_{i}$ from road dust, $t / a ; E_{R i}$ is the average emission coefficient of $P M_{i}$ from different categories of paved roads, $g /\left(\mathrm{km} \cdot\right.$ vehicle); $L_{R}$ is the length of road, $k m ; N_{R}$ is the average traffic flow on the road during a certain period of time, the vehicle/a; $n_{r}$ is the number of dust-free days; $k_{i}$ is the particle size multiplier of $P M_{i}$, the recommended value is $3.23 \mathrm{~g} / \mathrm{km}(T S P), 0.62 \mathrm{~g} / \mathrm{km}\left(\mathrm{PM}_{10}\right)$ and $0.15 \mathrm{~g} / \mathrm{km}\left(\mathrm{PM}_{2.5}\right)$; $\mathrm{sL}$ is road dust load, $\mathrm{g} / \mathrm{m}^{2} ; \mathrm{W}$ is the average vehicle weight, $\mathrm{t} ; \eta$ is the removal efficiency by pollution control technology, $\%$, when multiple measures are implemented simultaneously, the maximum removal efficiency should be taken as the final value.

In this study, days with precipitation exceed $0.25 \mathrm{~mm} / \mathrm{d}$ was taken as the number of dust-free days. In order to obtain the traffic flow data, a 10-day-long monitoring experiment was carried out on each category of paved roads to obtain traffic flow $\left(\mathrm{N}_{R}\right)$ and the road dust load of different types of road. The average vehicle weight and other traffic information were estimated based on the observation data, the emission parameters of different levels of roads in Zhengzhou are shown in Table 1.

Table 1

Emission parameters of different levels of roads

\begin{tabular}{|lllll|}
\hline Road type & $\begin{array}{l}\text { National } \\
\text { road }\end{array}$ & $\begin{array}{l}\text { Provincial } \\
\text { road }\end{array}$ & $\begin{array}{l}\text { County } \\
\text { road }\end{array}$ & Township road \\
\hline Traffic flow (vehicles/day) & 7579 & 6432 & 1500 & 850 \\
\hline Dust load (g/m²) & 0.27 & 0.33 & 0.52 & 1.57 \\
\hline Average weight ( $\mathrm{t})$ & 8.80 & 6.90 & 4.70 & 2.80 \\
\hline TSP emission coefficient (g/VKT) & 9.02 & 8.45 & 8.64 & 13.92 \\
\hline PM10 emission coefficient (g/VKT) & 1.73 & 1.62 & 1.66 & 2.67 \\
\hline PM2.5 emission coefficient (g/VKT) & 0.42 & 0.39 & 0.40 & 0.65 \\
\hline
\end{tabular}




\section{Results And Discussion}

\subsection{Emission Inventory and Spatial Distribution of PM from soil dust}

1259 piece of bare grounds were identified in Zhengzhou in 2016 with a total area of $68.97 \mathrm{~km}^{2}$, which were mainly distributed in Zhongmou and Xinzheng. Zhongmou has the largest exposed area, which accouts for $52.50 \%$ of the total area of bare ground in Zhengzhou, followed by Xinzheng, Dengfeng and Xinmi. (Fig. 2(a)). Figure 2(b), 2(c) and 2(d) display the spatial distribution of PM emission from soil dust source with a grid of $3 \mathrm{~km} \times 3 \mathrm{~km}$ resolution. Results show that the emission of $T S P, \mathrm{PM}_{10}$ and $\mathrm{PM}_{2.5}$ from soil dust source were $507.40 \mathrm{t} \cdot \mathrm{a}^{-1}, 45.53 \mathrm{t} \cdot \mathrm{a}^{-1}$ and $1.30 \mathrm{t} \cdot \mathrm{a}^{-1}$, respectively in Zhengzhou. The maximum PM emission from soil dust source concentrated in Zhongmou and Xinzheng, which is consistent with the distribution characteristic of bare grounds. The Airport Economy Zone also has high PM emission, the main reason is that the soil type is mainly silt soil, which can be easily raised into air by wind and human activities, therefore lead to high emission coefficient. Dengfeng has a complex terrain that decreases from north to south, Xinmi is surrounded with mountains, although the area of bare ground are not small in the two regions, the limitation of topography reduced the effects of wind and human farming activities and lead to low PM emission. Xingyang, Gongyi and the urban area of Zhengzhou have the minimum PM emission, and it is mainly due to the small area of bare grounds.

\subsection{Emission Inventory and Spatial Distribution of PM from construction dust}

The number of construction sites was 1,793 in Zhengzhou with a total area of $145.25 \mathrm{~km}^{2}$ in 2016 , which was mainly distributed in the urban area (Fig. 3(a)). The emission of $\mathrm{TSP} \mathrm{PM}_{10}$ and $\mathrm{PM}_{2.5}$ from construction dust source was calculated to be $181.5 \mathrm{kt} \cdot \mathrm{a}^{-1}, 93.0 \mathrm{kt} \cdot \mathrm{a}^{-1}$ and $19.8 \mathrm{kt} \cdot \mathrm{a}^{-1}$, respectively. Figure 3 showed the spatial distribution of PM emission from construction dust sources in Zhengzhou City in 2016. The result suggests that PM emission from construction dust is closely related to regional development degree. The emission of $\mathrm{TSP}, \mathrm{PM}_{10}$ and $\mathrm{PM}_{2.5}$ from construction dust sources are centered in 4 districts with high developed culture and economics, including Zhongyuan, Huiji, Jinshui and Zhengdong New District, the four regions formed a urban area-centered high emission circle. Zhongmou, Xingyang and Xinzheng, bordering the main urban area, also have high PM emission under the influence of regional conditions and urban economic radiation. Low PM emission area located in Gongyi and Dengfeng, which is far away from the main urban zone of Zhengzhou and lack of leading industries for economic development.

Compared with other cities in China, TSP emission from construction dust sources in Zhengzhou is 1.26 times of Beijing and 1.89 times of Wuhan, $\mathrm{PM}_{10}$ emission is 1.32 times of Beijing and 0.98 times of Wuhan, and PM2.5 emisson is 0.35 times of Beijing and 1.06 times of Wuhan[24-25]. It is assumed that the reason resulting in high PM emisson in Zhengzhou was the reconstruction of the urban village. The 
Government of Zhengzhou demand that all the urban villages within the fourth ring road of Zhengzhou should be demolished by the end of 2016. To complete the target on schedule, large number of construction work has been conducted in the main urban area in the year of 2016, which result in a substantial increase of PM emission from construction sources.

\subsection{Emission Inventory and Spatial Distribution of PM from Road dust}

The total length of paved roads in Zhengzhou in 2016 was 10,601.50 km, and the length of national road, provincial road, county road and township road were $396.30 \mathrm{~km}, 901.40 \mathrm{~km}, 2,439.88 \mathrm{~km}$ and $6,863.92 \mathrm{~km}$, respectively. It has been calculated that the total emission of TSP, $\mathrm{PM}_{10}$ and $\mathrm{PM}_{2.5}$ from paved roads were $55.5 \mathrm{kt} \cdot \mathrm{a}^{-1}, 10.7 \mathrm{kt} \cdot \mathrm{a}^{-1}$ and $2.6 \mathrm{kt} \cdot \mathrm{a}^{-1}$, respectively (Table 2). Among different levels of roads, township road has the largest PM emission, followed by provincial road, county road and national road. This is because the length of township road is far more than other types of roads, and the road dust load of township road is relatively large. Although the dust load of provincial road is small, the heavy traffic volume lead to high PM emissions. It can be seen that the TSP, $\mathrm{PM}_{10}$ and $\mathrm{PM}_{2.5}$ emission from road dust is large in Zhengzhou, but compared with other cities of similar size in China, PM emission from road dust in Zhengzhou are still at low level[26-27].

The spatial characteristics of TSP, $\mathrm{PM}_{10}$ and $\mathrm{PM}_{2.5}$ emission from road dust source in Zhengzhou was shown in Fig. 4b, c, d. For different levels of roads, high PM emission mainly concentrated in the main urban areas such as Zhongyuan, Huiji, Jinshui and Zhengdong New District, it is because the main urban region is the intersection of the Longhai Railway and the Beijing-Guangzhou Railway, besides, the 107 National Highway, the 310 National Highway, the Beijing-Hongkong-Macao Expressway and the Lianhuo Expressway all pass through the area. PM emission from roads is also higher in the junction of Zhongmou, Xingyang, Xinzheng and the main city in the area, and the emission of the area which are far from the urban area such as Shangjie and Dengfeng is small.

Table 2

Emission of $\mathrm{TSP}, \mathrm{PM}_{10}$ and $\mathrm{PM}_{2.5}$ from paved roads

\begin{tabular}{|lllll|}
\hline Type & Length(km) & TSP(t/a) & $\mathrm{PM}_{10}(\mathrm{t} / \mathrm{a})$ & $\mathrm{PM}_{2.5}(\mathrm{t} / \mathrm{a})$ \\
\hline State road & 396.30 & 7958.07 & 1527.56 & 369.57 \\
\hline Provincial road & 901.40 & 14387.84 & 2761.75 & 668.17 \\
\hline County road & 2439.88 & 9285.82 & 1782.42 & 431.23 \\
\hline Township road & 6863.92 & 23857.19 & 4579.40 & 1107.92 \\
\hline Total & 10601.50 & 55488.93 & 10651.13 & 2576.89 \\
\hline
\end{tabular}

\subsection{Total PM emissions from dust source}


The calculation results showed that the emission of TSP, $\mathrm{PM}_{10}$ and $\mathrm{PM}_{2.5}$ of Zhengzhou in 2016 were $237.5 \mathrm{kt} \cdot \mathrm{a}^{-1}, 103.7 \mathrm{kt} \cdot \mathrm{a}^{-1}$ and $22.4 \mathrm{kt} \cdot \mathrm{a}^{-1}$, respectively. By analyzing the source of $\mathrm{PM}$, it can be found that the construction dust was the main dust sources of PM emission in Zhengzhou, $T S P, \mathrm{PM}_{10}$ and $\mathrm{PM}_{2.5}$ emission from construction dust accounted for $76.43 \%, 89.69 \%$ and $88.50 \%$, respectively of total dust sources (Table 3 ).

The spatial distribution of total PM emission was shown in Fig. 5b, $5 c$ and $5 d$, it can be seen that the emission of TSP, $\mathrm{PM}_{10}$ and $\mathrm{PM}_{2.5}$ were mainly concentrated in the Zhongyuan, Huiji, Jinshui, Zhengdong New District and other main urban areas. Zhongmou, Xingyang and Xinzheng, which bordering with the main urban area, were also the high PM emission area. While the areas that far away from the main urban area had low emission intensity such as Shangjie and Dengfeng. Three aspects of reasons of the emission characteristics was concluded. Firstly, the majority of construction sites are distributed in the main urban area, secondly, the dense road network and heavy traffic flow of the main urban area increases the PM emission, moreover, although soil dust is more prevalent in the suburbs than in the urban area, but due to the small PM emission from soil dust, it doesn't make much difference to the general characteristic of total emissions.

Results from the analysis revealed that the key zones for PM emission control from dust sources are mainly distributed in the main urban area of zhengzhou, which is consist of Zhongyuan, Huiji, Jinshui, Zhengdong New District. Furthermore, areas such as Zhongmou, Airport Economy Zone and Xinzheng are more likely to face increasing serious PM emission problems due to the acceleration of urbanization under policy orientation, so it is necessary to conduct early prevention of PM emission in these potential PM emission areas.

Table 3

Emission of $\mathrm{TSP}, \mathrm{PM}_{10}$ and $\mathrm{PM}_{2.5}$ from dust sources

\begin{tabular}{|llllll|}
\hline Dust type & $\begin{array}{l}\text { Soil } \\
\text { dust }\end{array}$ & Construction dust & Road dust & Total \\
\hline TSP & Total annual emission $t \cdot a^{-1}$ & 507.40 & 181547.25 & 55488.93 & 237543.58 \\
\hline & percentage \% & 0.21 & 76.43 & 23.36 & 100 \\
\hline $\mathrm{PM}_{10}$ & Total annual emission $\mathrm{t} \cdot \mathrm{a}^{-1}$ & 45.53 & 93047.65 & 10651.13 & 103744.31 \\
\hline & percentage \% & 0.044 & 89.69 & 10.27 & 100 \\
\hline $\mathrm{PM}_{2.5}$ & Total annual emission $\mathrm{t} \cdot \mathrm{a}^{-1}$ & 1.30 & 19842.70 & 2576.89 & 22420.89 \\
\hline & percentage \% & 0.006 & 88.50 & 11.49 & 100 \\
\hline
\end{tabular}

\section{Conclusions}


Based on the remote sensing data and method recommended by Technical Guidelines for Emissions Inventory of Particulate Matter Emitted from Dust Source, total emission of TSP, $\mathrm{PM}_{10}$ and $\mathrm{PM}_{2.5}$ from soil dust, construction dust and road dust in 2016 were estimated, and the spatial distribution of PM emission was mapped in a grid of $3 \mathrm{~km} \times 3 \mathrm{~km}$ resolution based on RS-GIS approach. The total emission of TSP, $\mathrm{PM}_{10}$ and $\mathrm{PM}_{2.5}$ in Zhengzhou was $237.5 \mathrm{kt} \cdot \mathrm{a}^{-1}, 103.7 \mathrm{kt} \cdot \mathrm{a}^{-1}$ and $22.4 \mathrm{kt} \cdot \mathrm{a}^{-1}$, respectively in 2016. Construction dust source was

the main emission source in Zhengzhou, the $\mathrm{TSP}_{1} \mathrm{PM}_{10}$ and $\mathrm{PM}_{2.5}$ emission of which account for $76.42 \%$, $89.68 \%$ and $88.39 \%$, respectively of the total emissions. The TSP, $\mathrm{PM}_{10}, \mathrm{PM}_{2.5}$ emission are larger in main urban areas including Jinshui, Zhongyuan, Erqi, Jingkai and other urban districts, while Zhongmou, Xingyang, Dengfeng, Gongyi and other remote areas had small PM emission. The GIS-RS based approach provides an efficient way for identifying the emission characteristics in urban area, the emission inventory and the spatial distribution of PM emission from different dust sources in this study could be a practical guidance for the prevention and control of urban atmospheric pollution.

\section{Abbreviations}

PM: Particulate matter; TSP: Total suspended particles; $\mathrm{PM}_{10}$ : Particulate Matter less than $10 \mu \mathrm{m}$ in diameter; $\mathrm{PM}_{2.5}$ : Particulate Matter less than $2.5 \mu \mathrm{m}$ in diameter; MEP: the Ministry of Ecological Environment; GIS: Geographic Information System; RS: Remote Sensing.

\section{Declarations}

\section{Authors' email addresses:}

Huan Yang (huanyang_zzu@163.com)

Xuan Song (songxuan@zzu.edu.cn)

Jiarui Song (casongjiarui@Outlook.com)

Qi Zhang (15938183926@163.com)

Jian Cui (149375572@qq.com)

Shasha Yin (shashayin@zzu.edu.cn)

\section{Declarations}

Ethics approval and consent to participate: Not applicable.

Consent for publication: Not applicable. 
Availability of data and materials: The datasets used and/or analysed during the current study are available from the corresponding author on reasonable request.

Competing interests: The authors declare that they have no competing interests.

Funding: This research was supported by National Key R\&D Program of China (2017YFC0212401); CMA/Henan Key Laboratory of Agrometeorological Support and Applied Technique( AMF201610)

Author Contributions: HY performed the data analyses and wrote the manuscript; XS and SY proposed ideas of the study; QZ has been involved in data analyses. JS has been involved in revising the manuscript. JC have made substantial contributions in data acquisition. All authors read and approved the final manuscript.

Acknowledgments: Remote sensing data in the project was assisted by National Engineering Laboratory Geological Remote Sensing Center for Remote Sensing Satellite Application.

\section{References}

1. Feng YL, Chen YJ, Guo H, Zhi GR, Xiong SC, Li J, Sheng GY, Fu JM: Characteristics of organic and elemental carbon in PM2.5 samples in Shanghai, China. Atmospheric Research 2009, 92(4):434442.

2. Chan YC, Simpson RW, McTainsh GH, Vowles PD, Cohen DD, Bailey GM: Characterisation of chemical species in PM2.5 and PM10 aerosols in Brisbane, Australia. Atmospheric Environment 1997, 31(22):3773-3785.

3. Tunno BJ, Shields KN, Paul L, Lioy P, Chu NJ, Kadane JB, Parmanto BB, Pramana G, Zora J, Davidson C, Holguin F, Clougherty JE: Understanding intra-neighborhood patterns in PM 2.5, and PM 10, using mobile monitoring in Braddock, PA. Environmental Health 2012, 11(1):76.

4. Cohen AJ, Ross Anderson H, Ostro B, Pandey KD, Krzyzanowski M, Kunzli N, Gutschmidt K, Pope A, Romieu I, Samet JM, Smith K: The global burden of disease due to outdoor air pollution. Toxic Environ Health 2005, 68(13-14):1301-1307.

5. Dappe V, Uzu G, Schreck E, Wu L, Li X, Dumat C, Moreau M, Hanoune B, Ro CU, Sobanska S: Singleparticle analysis of industrial emissions brings new insights for health risk assessment of pm. Atmospheric Pollution Research 2018, 9(4):697-704.

6. Xu GY, Ren XD, Xiong KN, Li LQ, Bi XC, Wu QL: Analysis of the driving factors of PM2.5 concentration in the air: A case study of the Yangtze River Delta, China. Ecological Indicators 2020, 110. https://doi.org/10.1016/j.ecolind.2019.105889

7. Khanna I, Khare M, Gargava P, Khan AA: Effect of PM2.5 chemical constituents on atmospheric visibility impairment. Journal of the Air \& Waste Management Association 2018, 68(5):430-437.

8. Wang Sk, Wang TJ, Shi R, Tian J: Estimation of different fugitive dust emission inventory in Nanjing. Journal of University of Chinese Academy of Sciences 2014, 31(3): 351-359. 
9. Shu L, Luo B, Hu J, Xia J, Zhang LY, Luo B, Zhong LJ, Zhang ZQ: Emission inventory and characteristics of atmospheric PM2.5 and PM10 in Nanchong City. China Environmental Monitoring 2018, 34(3):84-92.

10. Song N, Xu H, Bi XH, Wu JH, Zhang YF, Yang HH, Feng YC: Source apportionment of PM2.5 and PM10 in Haikou. Environmental Science Research 2015, 28(10):1501-1509.

11. Wu H, Zhang CY, Wang J, Xuan ZF, Chu CJ, Feng YC, Xu H: Comparative study of pollution characteristics and source apportionment of PM10 and PM2.5 in Qingdao. Environmental Science Research 2013, 26(6):583-589.

12. Kong SF, Han B, Bai ZP, Chen L, Shi JW, Xu Z: Receptor modeling of PM2.5, PM10 and TSP in different seasons and long-range transport analysis at a coastal site of Tianjin, China. Science of The Total Environment 2010, 408(20):4681-4694.

13. Li Z, Chen C, Wang P, Chen ZG, Cao SJ, Wang QQ, Xie GY, Wan YL, Wang YF, Lu B: Influence of atmospheric fine particulate matter (PM 2.5) pollution on indoor environment during winter in Beijing. Building and Environment 2015, 87:283-291.

14. Zhang K, Zhou L, Fu QY, Yan L, Morawska L, Jayaratne R, Xiu GL: Sources and vertical distribution of PM2.5 over Shanghai during the winter of 2017. Science of The Total Environment 2019, https://doi.org/10.1016/j.scitotenv.2019.135683.

15. Perrino C, Tiwari S, Maria C, Torre SD, Rantica E, Canepari S: Chemical characterization of atmospheric PM in Delhi, India, during different periods of the year including Diwali festival. Atmospheric Pollution Research 2011, 2(4):418-427.

16. Wang XY, Lei Y, Yan L, Liu T, Zhang Q, He KB: A unit-based emission inventory of SO2, NOx and PM for the Chinese iron and steel industry from 2010 to 2015. Science of The Total Environment 2019, 676:18-30.

17. Yu ZH, Liscinsky DS, Fortner EC, Yacovitch TI, Croteau P, Herndon SC, Miake-Lye RC: Evaluation of PM emissions from two in-service gas turbine general aviation aircraft engines. Atmospheric Environment 2017, 160:9-18.

18. Mousavi A, Sowlat MH, Hasheminassab S, Pikelnaya O, Polidori A, Ban-Weiss G, Sioutas C: Impact of particulate matter (PM) emissions from ships, locomotives, and freeways in the communities near the ports of Los Angeles (POLA) and Long Beach (POLB) on the air quality in the Los Angeles county. Atmospheric Environment 2018, 195:159-169.

19. Maricq MM, Szente JJ, Harwell AL, Loos MJ: Impact of aggressive drive cycles on motor vehicle exhaust PM emissions. Journal of Aerosol Science 2017, 113:1-11.

20. Zhengzhou Environmental Quality Bulletin [EB/OL]. http://public.zhengzhou.gov.cn/service140201/442839.jhtml

21. Ministry of Environmental Protection: Technical guide for the preparation of dust particles discharge list (for trial implementation) 2015. (http://www.mep.gov.cn)

22. Yang B, Wang M, Xu W, Li DR, Gong JY, Pi YD: Large-scale block adjustment without use of ground control points based on the compensation of geometric calibration for ZY-3 images. ISPRS Journal 
of Photogrammetry and Remote Sensing 2017, 134:1-14.

23. Ni WJ, Sun GQ, Ranson KJ, Pang Y, Zhang ZY, Yao W: Extraction of ground surface elevation from ZY-3 winter stereo imagery over deciduous forested areas. Remote Sensing of Environment 2015, 159(15):194-202.

24. Xue YF, Zhou Z, Huang YH, Wang K, Nie T, Nie L, Qin JP: Fugitive dust emission characteristics of building construction sites in Beijing. Environmental Science 2017, 38 (6):2231-2237.

25. Huang Y, Hu CJ, Cheng HR, Wang ZW: Emission inventory and spatial distribution characteristics of particulate matter dust Source in Wuhan, China. Journal of Wuhan University (Science and Technology) 2018, 64(4):354-362.

26. Tong XN, Qiao YZ, Yao SS, Zhang J: Emission Inventory of construction fugitive dust in Nanjing. Environmental Monitoring Management and Technology 2014, 26(3):21-24.

27. Li TK, Bi XH, Dai QL, Liu BS, Han Y, You HY, Wang L, Zhang JY, Cheng Y, Zhang YF, Wu JH, Tian YZ, Feng YC: Improving spatial resolution of soil fugitive dust emission inventory using RS-GIS technology: An application case in Tianjin, China. Atmospheric Environment 2018, 191:46-54.

\section{Figures}

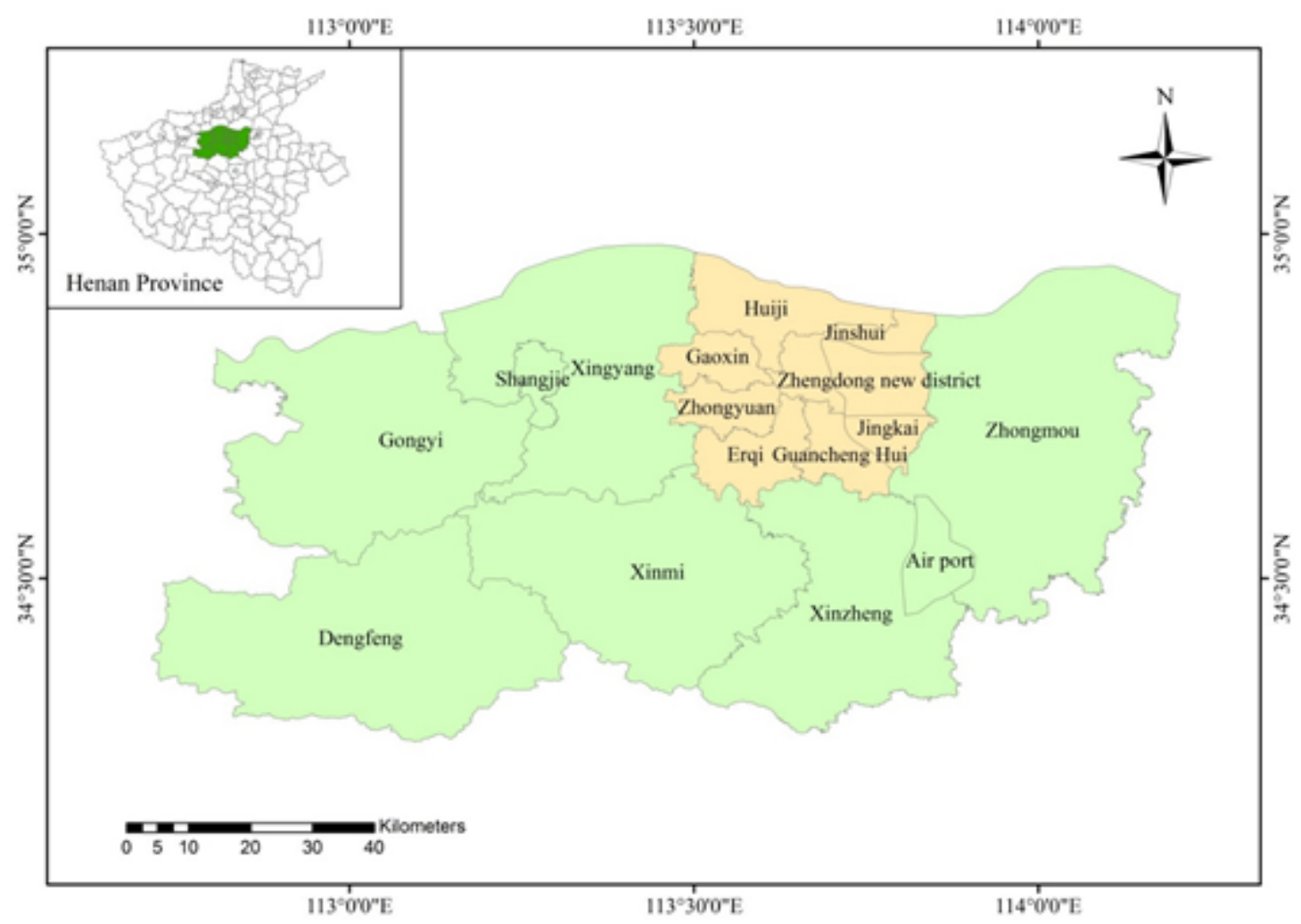

Figure 2

Geographic location and administrative district of Zhengzhou. Note: The designations employed and the presentation of the material on this map do not imply the expression of any opinion whatsoever on the 
part of Research Square concerning the legal status of any country, territory, city or area or of its authorities, or concerning the delimitation of its frontiers or boundaries. This map has been provided by the authors.

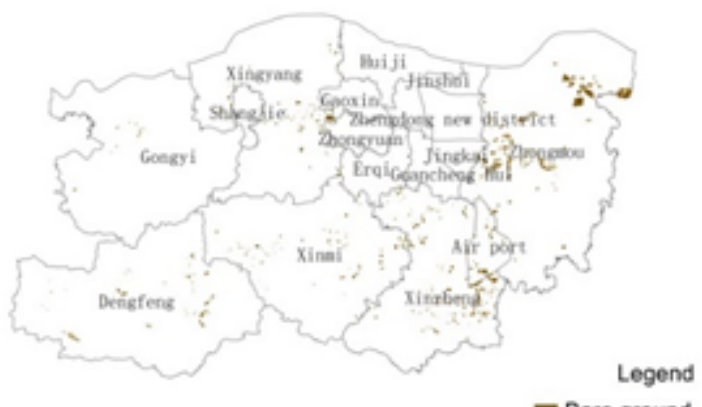

(a) Bare ground distribution

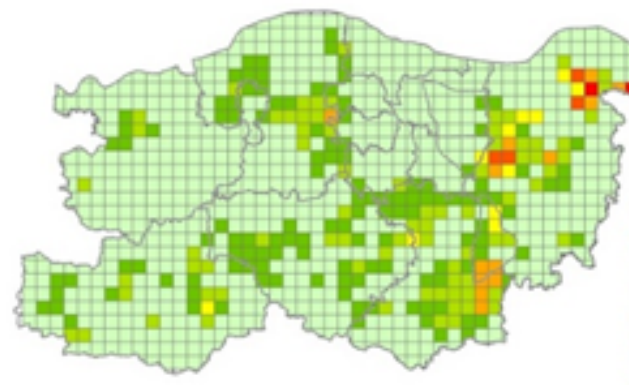

(c) PM10 annual emissions
- Bare ground

$\square$ Administrative division

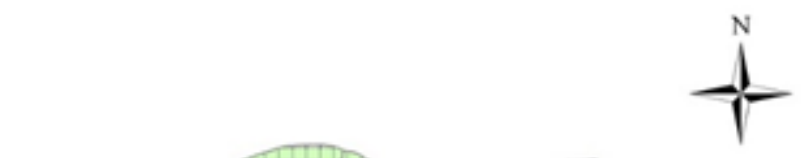

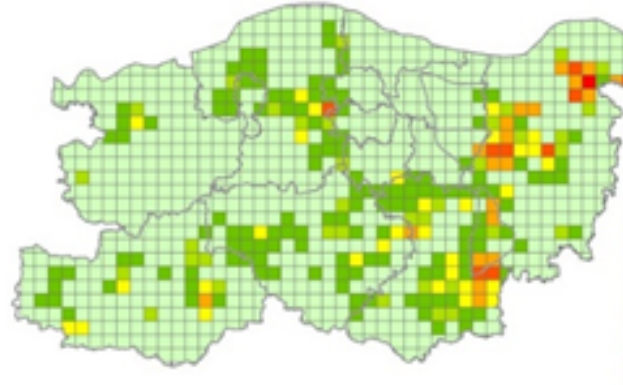

(b) TSP annual emissions
TSP ( ta )

$\square 0$

$>0-1.326$

$\square>1.326=2.490$

$\square>2.490-4.414$

ㅁ. $>4.414 \cdot 7.906$

[1. $>7.906-14.959$

- $>14.959-26.868$
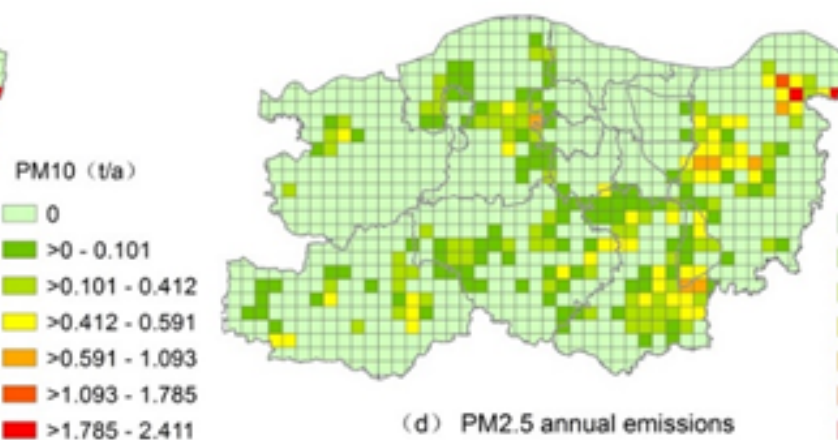

(d) PM2.5 annual emissions

PM2.5 (t/a)

$\square 0$

$>0-0.0019$

$0.0020-0.0070$

$\square>0.0070=0.0210$

$=0.0210 \cdot 0.0349$

$>0.0349-0.0491$

$>0.0491-0.0690$

\begin{tabular}{lllll}
0 & 15 & 30 & 60 & 90 \\
\hline & & &
\end{tabular}

\section{Figure 4}

Spatial distribution of PM emission from bare ground. Note: The designations employed and the presentation of the material on this map do not imply the expression of any opinion whatsoever on the part of Research Square concerning the legal status of any country, territory, city or area or of its authorities, or concerning the delimitation of its frontiers or boundaries. This map has been provided by the authors. 


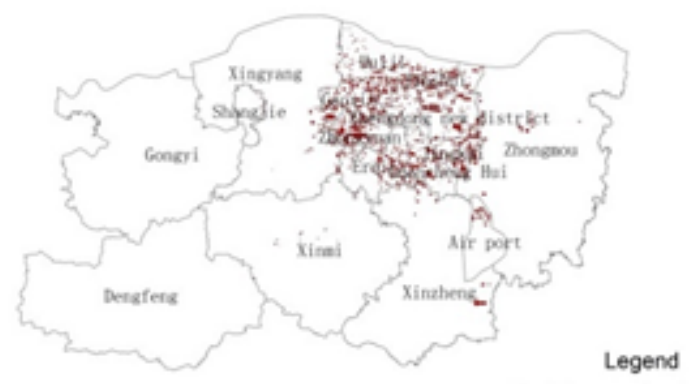

(a) Construction distribution
- The construction site $\square$ Administrative division

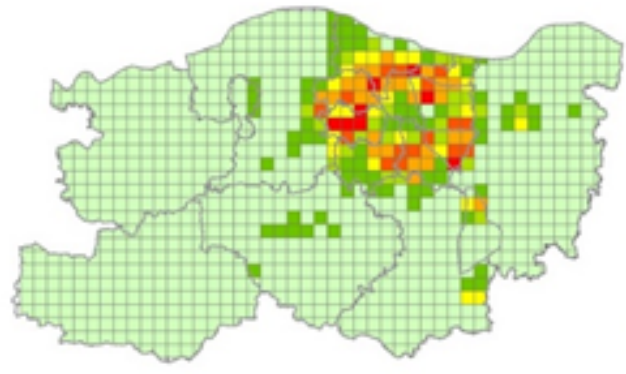

(b) TSP annual emissions

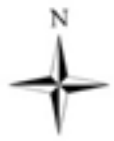

TSP ( Va)

$\square 0$

$>0.235$

$>235-475$

$\square>475 \cdot 774$

$>774-1152$

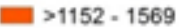

[ $>1569-2873$

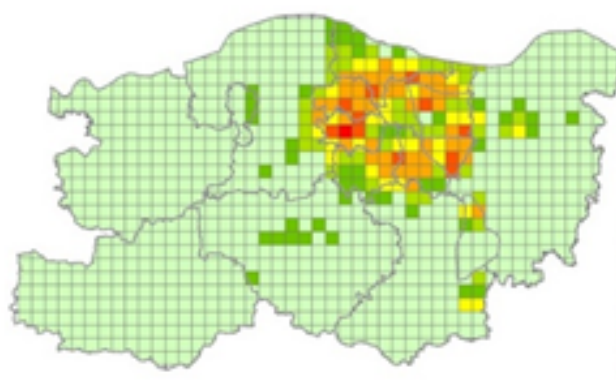

(d) PM2.5 annual emissions

PM2.5 (t/a)

$\square 0$

$>0.27$

$>27-82$

$\square>82 \cdot 154$

$\square>154-305$

$>305-445$

(c) PM10 annual emissions

$>2067-2873$

\begin{tabular}{lllll}
0 & 15 & 30 & 60 & 90 \\
\hline
\end{tabular}

\section{Figure 6}

Spatial distribution of PM emission from construction sites. Note: The designations employed and the presentation of the material on this map do not imply the expression of any opinion whatsoever on the part of Research Square concerning the legal status of any country, territory, city or area or of its authorities, or concerning the delimitation of its frontiers or boundaries. This map has been provided by the authors. 


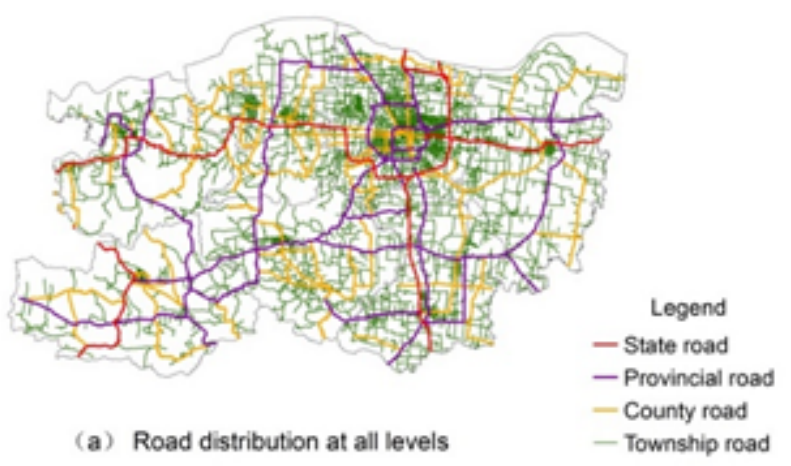

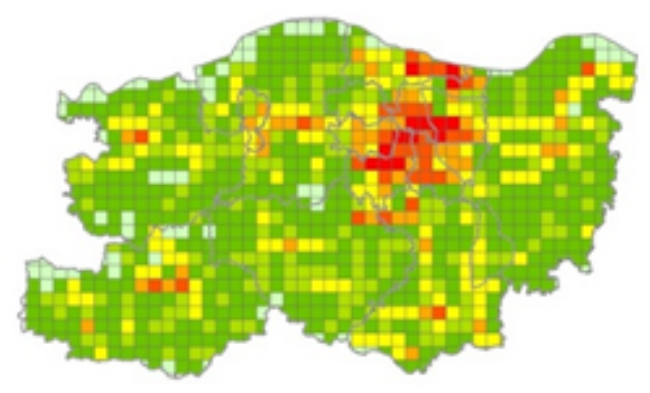

(b) TSP annual emissions

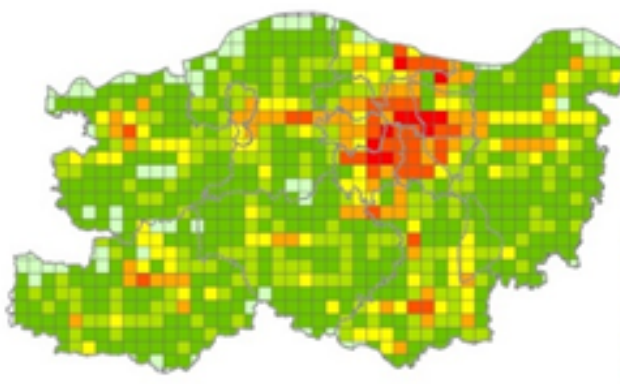

(d) PM2.5 annual emissions

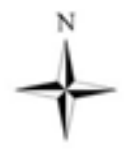

TSP (t/a)

$\square 0$

$>0.23$

$\square>23-41$

$\square>41.65$

$>65-94$

$>94=139$

- $>139-215$

PM2.5 (Va)

0

$>0-1.48$

$>1.48-2.63$

$\square>2.63-3.96$

$>3.96 \cdot 6.00$

$>6.00 \cdot 9.37$

$>9.37-13.73$

\section{Figure 8}

Spatial distribution of PM emission from paved roads. Note: The designations employed and the presentation of the material on this map do not imply the expression of any opinion whatsoever on the part of Research Square concerning the legal status of any country, territory, city or area or of its authorities, or concerning the delimitation of its frontiers or boundaries. This map has been provided by the authors. 

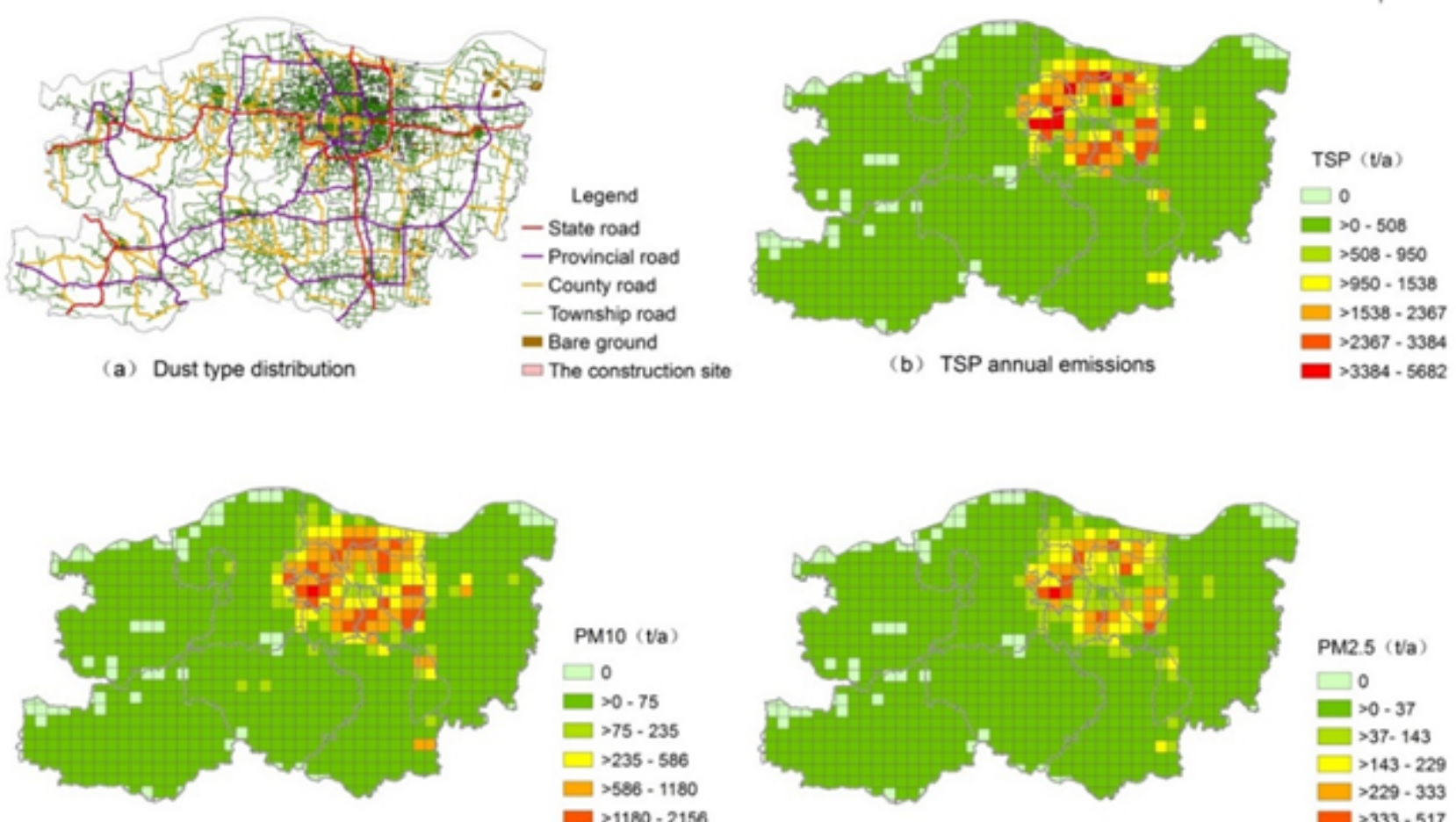

(c) PM10 annual emissions

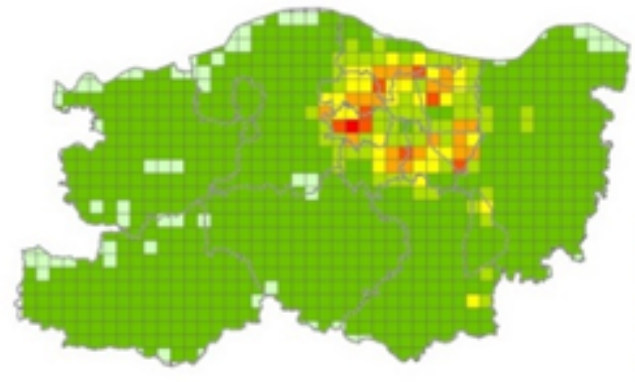

(d) PM2.5 annual emissions

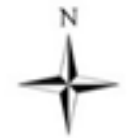

PM2.5 (t/a)

$\square 0$

$>0-37$

[- $>37 \cdot 143$

$\square>143-229$

$>229-333$

[2156 - 2891

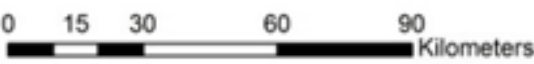

Figure 9

Spatial distribution of total PM emission from dust sources. Note: The designations employed and the presentation of the material on this map do not imply the expression of any opinion whatsoever on the part of Research Square concerning the legal status of any country, territory, city or area or of its authorities, or concerning the delimitation of its frontiers or boundaries. This map has been provided by the authors.

\section{Supplementary Files}

This is a list of supplementary files associated with this preprint. Click to download.

- Formulas.docx

- Formulas.docx 